\title{
Erratum to: Effect of High-Temperature Gas-Chemical Modification on the Structural and Functional Properties of Carbon Black Particles
}

Yu. V. Surovikin $a *$, A. G. Shaitanov ${ }^{a}$, I. V. Rezanov $a$, A. V. Syr'eva ${ }^{a}$, V. A. Likholobov ${ }^{a}$, A. N. Poddubnyak ${ }^{b}$, and K. K. Chigrin $b$

a Institute of Hydrocarbons Processing, Siberian Branch, Russian Academy of Sciences, ul. Neftezavodskaya 54, Omsk, 644040 Russia

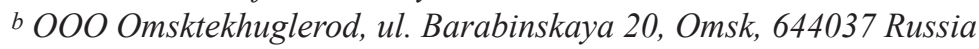

*e-mail:suruv@ihcp.ru

Received November 7, 2018

DOI: $10.1134 / \mathrm{S} 1070427218100233$

Figure 6 in the page 1980 should be replaced by the following:

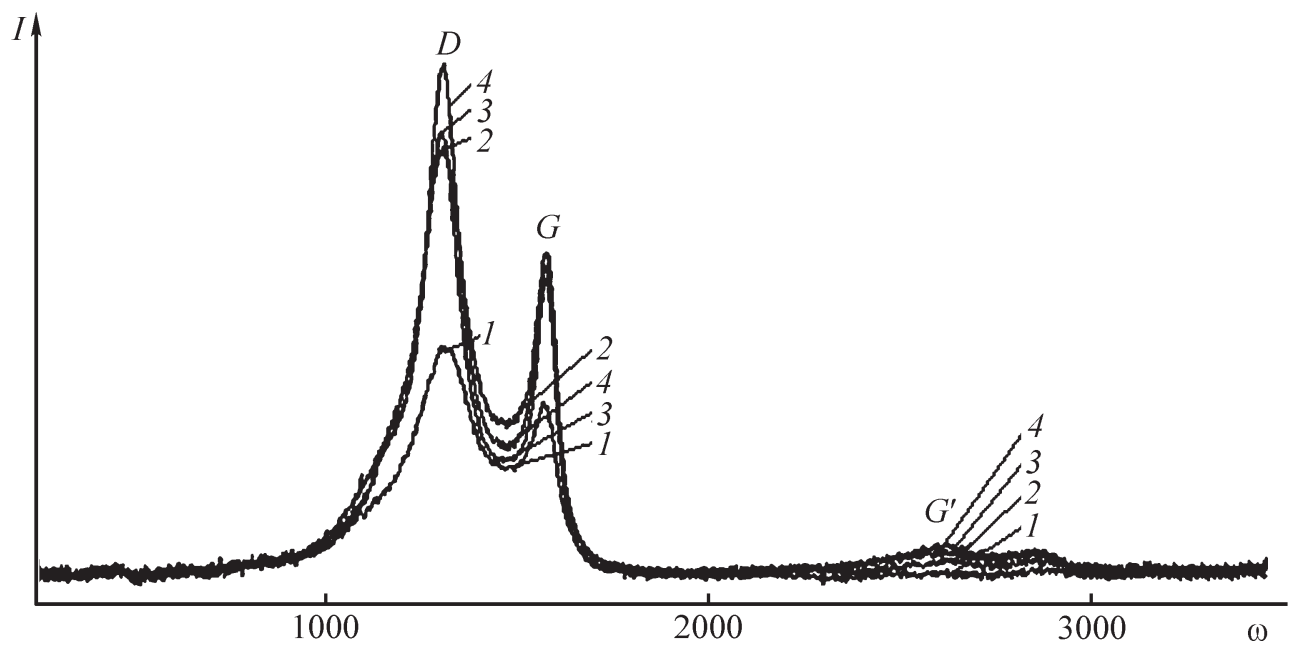

The original article can be found online at https://doi.org/10.1134/S1070427217120126 